\title{
Introduction to the Virtual Issue: Election Fraud and Electoral Integrity
}

\author{
Ines Levin \\ Department of Political Science \\ University of Georgia \\ Athens, GA 30602 \\ email: ilevin@uga.edu \\ R. Michael Alvarez \\ Division of Humanities and Social Sciences \\ California Institute of Technology \\ Pasadena, CA 91125 \\ email: rma@hss.caltech.edu
}

\section{Election Fraud and Electoral Integrity}

Throughout the world, elections are being used in increasing numbers of nations. Conducting elections is seen as providing legitimacy to elected leaders, as long as they are conducted fairly and with integrity. But it also seems that along with the trends toward more elections around the world there are increasing concerns about electoral fraud and the potential manipulation of the electoral process. For example, recent presidential elections in Mexico have been marred by allegations of fraud and vote buying, including claims that PRI supporters in some areas provided gift cards to voters. ${ }^{1}$ Concerns about electoral fraud, manipulation and anomalous results have swirled around recent elections in Afghanistan (Worden 2010), Angola (Collier and Vicente 2012), Armenia (Hyde 2007), Iran (Mebane 2010), Georgia (Tucker 2007), Kenya (Collier and Vicente 2012), Kyrgyzstan (Tucker 2007), Mexico (Eisenstadt 2007), Moldova (Senyuva 2010), Russia (Myagkov et al. 2009), Serbia (Tucker 2007), Ukraine (Myagkov et al. 2009; Tucker 2007), Venezuela (Levin et al. 2009), and Zimbabwe (Collier and Vicente 2012) — to name a few of the recent prominent examples. Similar concerns have arisen about some anomalies in recent U.S. elections as well, for example a dispute over the Thirteenth Congressional District's election in $2006 .^{2}$

Provoked by election controversies in the past decade, political methodologists have been at the forefront of studying both election fraud and election integrity. This Virtual Issue of Political Analysis presents a number of those recent papers, highlighting the contributions that methodologists have made in developing new approaches to analyze elections data to try to detect anomalies that might indicate the existence of deliberate manipulation that could constitute electoral fraud. Other methodologists have taken a different approach, and while not motivated to detect manipulation or fraud, they have developed analytic approaches that help us better understand and predict election results, and which can be used in the future to improve evaluations of election integrity and analyses of the causes and consequences of election fraud.

\section{This Virtual Issue}

In the first section of this introduction, we summarize some of the main results and contributions of four recent papers concerned directly with development and improvement of techniques for detecting voter fraud. Then, we discuss the contributions of three papers that focus on methodologies for: testing hypotheses related to the impact of variables of interest on election outcomes; selecting elections for study in cross-national studies of electoral integrity; and improving the quality of election forecasts. Even though some of the papers included in the latter set are not directly concerned with the evaluation of electoral integrity, they have important implications for the future development of

\footnotetext{
${ }^{1}$ http://www.washingtonpost.com/world/mexicos-presidential-election-tainted-by-claims-of-votebuying/2012/07/04/gJQAHqTzNW_story.html

${ }^{2}$ See Jefferson 2007; Frisina et al. 2008.
} 
methodologies for the study of election fraud and electoral integrity. We conclude by discussing methodological issues that need to be addressed by researchers, and by proposing potential directions for future research. The following is a list of the seven papers included in the virtual issue:

- Election Fraud Forensics

- Joseph Deckert, Mikhail Myagkov and Peter C. Ordeshook, "Benford's Law and the Detection of Election Fraud.” Political Analysis (2011), 19: 245-268.

- Walter R. Mebane Jr., "Comment on "Benford's Law and the Detection of Election Fraud." Political Analysis (2011), 19: 269-272.

- Bernd Beber and Alexandra Scacco, "What the Numbers Say: A Digit-Based Test for Election Fraud." Political Analysis (2012), 20: 211-234.

- Francisco Cantu and Sebastian M. Saiegh, "Fraudulent Democracy? An Analysis of Argentina's Infamous Decade Using Supervised Machine Learning." Political Analysis (2011), 19: 409-433.

- Integrity of Elections

- Devin Caughey and Jasjet S. Sekhon, "Elections and the Regression Discontinuity Design: Lessons from Close U.S. House Races, 1942-2008." Political Analysis (2011), 19: 385-408.

- Susan D. Hyde and Nikolay Marinov, "Which Elections Can Be Lost?" Political Analysis (2012), 20: 191-210.

- Kari Lock and Andrew Gelman, "Bayesian Combination of State Polls and Election Forecasts." Political Analysis (2010), 18: 337-348.

The first set of papers in the virtual issue is concerned with election forensics, or the development of dataanalysis tools for detecting discrepancies between reported (observed) and real (unobserved) election outcomes. Most of these techniques try to find "outliers" in the data - for instance, patterns in the data that deviate from an expected distribution - and the presence of outliers is used to flag precincts or electoral jurisdictions where a miscount or manipulation of election returns might have taken place. Election forensic techniques developed and applied to date include the detection of: anomalies in turnout distributions and in the relationship between turnout and vote shares (Myagkov et al. 2009); anomalies in the flow of votes between elections (Myagkov et al. 2009); deviations from predicted vote shares (Alvarez and Katz 2008); and anomalies in digit distributions (Beber and Scacco 2012; Cantu and Saiegh 2011; Mebane 2008). Among election forensics techniques based on digit analysis of election returns, the study of deviations from Benford's Law constitutes one of the most commonly applied procedures outside the academic literature. According to Benford's Law, many real-world data generating processes produce counts where numbers 0 through 9 do not show up with similar frequencies within the digits composing the counts under study (as one might intuitively expect), but following a particular pattern where lower numbers are observed more frequently than higher numbers (specially within the first two digits). Benford's Law has been use in the past as a tool for detecting anomalies in financial statements, and more recently also in election returns; and deviations from BL's expectations have been interpreted as evidence of fraud of various kinds.

The first paper in the virtual issue, by Deckert, Myagkov, and Ordeshook (2011), shows that the use of Benford's Law for detecting anomalies in the second digit of election returns (2BL) is problematic, as deviations from the law can occur when elections are free and fair, and conversely, deviations might not occur following an overt manipulation of election returns. First, the authors criticize 2BL for the lack of a theory or model supporting the claim that election returns in free and fair elections should exhibit the patterns suggested by the law, and for the lack of an explanation as to why episodes of fraud should lead to deviations from expected patterns. After that, they simulate artificial data for free and fair, as well as fraudulent elections, based on the spatial model of voting, and use these data to show that $2 \mathrm{BL}$ leads to false positives and false positives with very high frequency. They show that technique is particularly problematic when districts are large and after a landslide victory. Lastly, the authors apply the forensic indicator to data from Ukraine's 2004 presidential election (where previous evidence suggests there was artificially inflated turnout in the first round of the presidential runoff); Ukraine's 2007 presidential election (where contextual information suggests there was fraud in the form of transfer of votes from one party to the other); and 
Russia's 2008 election (where authors suggest there are reasons to believe certain regions of the country are more vulnerable to fraud than others). They find that $2 \mathrm{BL}$ does not detect the expected patterns of voter fraud in any of these real-world data sets. One important contribution of the paper is that it helps correct misconceptions about the accuracy of 2BL for detecting election fraud. But most importantly, the research and discussion done by Deckert et al. are significant for their contribution to the development of general standards for the application of election forensic tools: indicators should have a sound theoretical or behavioral basis (that is, there should be an explanation or model of the relationship between electoral behavior and output produced by the indicator); and scholars applying these tools should have adequate knowledge of the substantive context of the election (such as knowledge of which regions of the country are more vulnerable to fraud, and what specific types of fraud to look for).

The second paper in the virtual issue, by Mebane (2011), is a response to Deckert et al.'s (2011) paper on the limitations of Benford's Law discussed in the previous paragraph. The author agrees that results produced by 2BL do not represent unequivocal evidence of the occurrence of fraud, and with the observation that 2BL still lacks a theoretical foundation. However, Mebane disagrees with certain arguments made by Deckert et al., and points out different reasons for the poor performance of $2 \mathrm{BL}$ in the simulation study - specifically, that data generated by drawing from normal distributions, as Deckert et al. do for some of the parameters of the spatial voting model, are unlikely to satisfy Benford's Law; and that the spatial voting model is unlikely to produce data resembling that of realworld elections. The author also points out that due to the high level of aggregation, it is not surprising that 2BL does not detect the expected patterns of fraud in the Ukrainian data, as well as in some of the artificially simulated data. In spite of the disagreements, Deckert et al. and Mebane's papers have in common that they encourage scholars to work on the improvement of election forensic indicators, by thinking more thoroughly about their theoretical or behavioral foundations-for instance, both papers mention that behaviors such as strategic voting may affect digit distributions and lead to deviations from expected patterns, implying that scholars should also work on the development of criteria for distinguishing between deviations that are caused by fraud, and deviations that are caused by other factors.

The third paper in the virtual issue, by Beber and Scacco (2012), develops an alternative digit-based test. Similarly to Benford's law, the test involves the detection of deviations from an expected digit distribution. But contrarily to $2 \mathrm{BL}$, it focuses on the distribution of the last two digits, instead of the second digit. Moreover, in contrast to $2 \mathrm{BL}$ - which has been criticized for the lack of a theoretical foundation - Beber and Sacco's test is based on abundant experimental evidence regarding heuristics employed by humans when asked to generate numbers in a random fashion: such as preference for small numbers (except for zero; and particularly 1,2, and 3); avoidance of repetition when writing down pairs of integers; and preference for adjacent pairs over distant pairs of integers. Berber and Scacco begin by showing that the last two digits of election returns resulting from free and fair elections are most likely uniformly distributed, and that manipulations involving human attempts at random number generation are likely to lead to deviations from the uniform distribution. After that, they apply their procedure to data from an unsuspicious election (Sweden's 2002 parliamentary election), and to a case where contextual knowledge of the election suggests politicians manipulated election returns by filling results sheet in an arbitrary manner (Nigeria's 2003 presidential election). While Sweden's results are in line with what one would expect in the context of a free and fair election, the distribution of last two digits in the Nigerian data deviates considerably from uniformity. They also apply their indicators to one allegedly fraud-free and one allegedly fraud-ridden election in Senegal (the 2000 and 2007 presidential elections), and while they do not find any suspicious pattern in the first case, they do find considerable deviations from uniformity in the second election. The digit-based test developed by Beber and Scacco represents an important contribution to the election forensics toolbox, as it can be applied in situations where it is not possible to apply alternative indicators - for instance, due to the absence of control variables and other pieces of information that often remain unavailable, such as turnout figures, results from previous elections, and aggregate socio-demographic covariates.

The fourth paper in the virtual issue, by Cantu and Saiegh (2011), develops a method for detecting voter fraud based on the generation of synthetic data sets. The method consists of the following steps: First, the authors generate artificial electoral data for free and fair and fraudulent elections; using an authentic validation data set to calibrate the parameters of the simulation model. The resulting simulated data sets contain binary indicators of the occurrence of fraud, as well as election forensic indicators - in particular, information about the frequency of first digits in simulated election returns, which the authors use to search for fraud based on first digit Benford's Law (1BL). Subsequently, conditional probabilities of the occurrence of fraud are estimated by regressing simulated fraud 
indicators on simulated election forensics indicators (in this case, first moment of the distribution of first digits), using a logistic link function. Lastly, a Naive Bayes classifier is used to cluster authentic electoral data into fraudulent or clean categories, based on the frequency of first-digits in the authentic data under study. Cantu and Saiegh apply their method to electoral data from gubernatorial and legislative elections taking place in the province of Buenos Aires between 1931 and 1941, during Argentina's "Infamous decade," and find evidence of electoral manipulation consistent with fraud allegations and accounts of the time. This paper makes an important contribution to the literature by showing how - by passing forensic indicators as input to automated clustering routines such as a Naive Bayes classifier - election forensic tools can be used to label election outcomes as "free and fair" or "fraudulent" in a non-arbitrary manner.

The last three papers included in the virtual issue do not deal directly with the development of election forensic indicators and procedures, but introduce or discuss methodologies that might contribute to the future development of techniques for evaluating the integrity of elections.

In the fifth paper in the virtual issue, Caughey and Sekhon (2011) point out weaknesses of a regression discontinuity design (RDD) used by Lee (2008) to measure the causal effect of incumbency on electoral outcomes. RDDs can be used in situations where assignment to treatment is determined by a continuous variable: such that for values of the assignment variable above a cutoff value, the observation is assigned or exposed to the treatment, and otherwise it is not. The idea underlying this technique is that for values of the assignment variable close to the cutoff, observations only differ in terms of treatment assignment, but are balanced in terms of pre-treatment attributes. This design can be used to measure the effect of the treatment on an outcome variable, by comparing outcomes among treated and non-treated observations around the cutoff point. For instance, Lee (2008) compares the electoral fortunes of candidates who just-won and just-lost a previous election, under the assumption that the only difference between both candidates is their incumbency status. In this particular application, the assignment variable is the voter share, and the cutoff value is the minimum vote share required to win the election. Caughey and Sekhon compare candidates who managed to get a plurality of the vote, with those who did not, and find that there is considerable imbalance in pre-treatment variables between both types of candidates - implying that it might be wrong to attribute the full extent of differences in electoral outcomes to incumbency advantage. Among the factors driving the share of the vote above the cutoff value considered by the authors, are manipulation of electoral outcomes and of vote recounts - although Caughey and Sekhon dismiss electoral fraud as a likely explanation of the observed imbalance in pre-treatment variables in the set of elections under consideration. This paper could have important implications for the development of election forensic techniques. The observation that electoral manipulation could be responsible for getting the vote share of certain candidates above a cutoff value raises the interesting question of whether quasi-experimental techniques such as RDD could be used in combination with election forensic indicators to detect instances of electoral fraud-for instance, by applying election forensic indicators to jurisdictions where the vote share of a particular party fell just-below and just-above a relevant cutoff value.

The next paper in the virtual issue, by Hyde and Marinov (2012), proposes a new criterion for selecting observations for study in the context of comparative electoral research. While other articles included in the virtual issue take electoral data as given and focus on developing statistical techniques for analyzing election outcomes; this paper focuses on the development of a criteria for selecting which elections to focus on. Why is this important? After the fall of an autocratic or hegemonic regime, some countries do not democratize fully, but turn into "semidemocracies" where elections are held but are either not truly competitive or the incumbent is willing to stay in power by manipulating electoral outcomes. If the election is not truly competitive - because the incumbent is running unopposed or because those candidates posing a real challenge to the incumbent are not allowed to run - then including this election in a study of the causes and consequences of electoral fraud could lead to biased inferences, as the incumbent is already sure to win and has no incentive to manipulate the electoral outcome. Conversely, if the pre-electoral context is not fair towards the opposition - for instance, because the incumbent has advantages in terms of campaign spending and advertising - but there is still an opposition challenger with a non-negligible chance of winning the election, then the incumbent might have real incentives to manipulate the electoral outcome in order to ensure a victory. While including countries with fully noncompetitive elections in cross-national studies of electoral fraud can be problematic, disregarding countries holding partially competitive elections may also lead to biased inferences. Hyde and Marinov (2012) point out that, in order to prevent these selection problems, the universe of cases should comprehend all elections that could potentially be lost. Authors introduce a new, minimalist, measure 
of regime type based on the competitiveness of the election. Subsequently, they apply the new and alternative measures to a study of the effect of media bias on electoral outcomes, and find that existing measures lead to biased inferences of the effect of media bias on the likelihood that the incumbent party loses the election. We expect that the findings and methodology introduced in this paper will have important implications for future cross-national studies of the determinants and consequences of election integrity.

Existing empirical studies of election integrity, as well as applications of election forensic indicators, are mostly based on the analysis of aggregate election returns. Public opinion survey data are not considered reliable enough as direct evidence of electoral malfeasance, and as a results have been disregarded by students of electoral fraud. However, the fact that survey data does not provide direct evidence of the occurrence of fraud does not mean it cannot be used to inform election forensic analysis. Lehoucq (2003, page 235) characterizes scientific surveys as a "largely unexploited source of information." The last paper in the virtual issue, by Lock and Gelman (2010), makes an important contribution by introducing a methodology that can be used to combine information about election returns (from past elections) and pre-election polls to produce better predictions of electoral outcomes, as well as more accurate measures of predictive uncertainty. How is this relevant for the detection of voter fraud? Students of electoral fraud often search election outcomes for deviations from expected patterns. One possible way of coming up with "expected" patterns is by forecasting vote shares based on information about previous election outcomes, using a regression approach (see, for example, Alvarez and Katz 2008). The Bayesian inference technique proposed by Lock and Gelman (2010) offers considerable promises, as it could be used to construct expected patterns of election returns not only based on previous election results, but also based on information contained in national- and regional-level pre-election polls. Most importantly, Bayesian inference allows taking into account the full extent of uncertainty in predicted vote shares, and thus improving the quality of tests of hypotheses related to the occurrence of voter fraud.

\section{Conclusion}

As we noted at the beginning of this essay, methodologists have stepped forward in the past decade to be directly involved in debates about the integrity of elections throughout the world - and specifically with regard to allegations of election fraud. These papers published recently in Political Analysis highlights these contributions, and also leads us to note the need for continued efforts by methodologists to study these important issues.

One concern regards the need for conceptual and theoretical research. As Alvarez, Hall and Hyde (2008) noted, "The relative nature of election fraud and the widely variant historical, cultural and institutional contexts in which election fraud has occurred make the development of a clear and consistent definition (of electoral fraud) a complicated, if not impossible, undertaking." A recent survey of electoral fraud by the International Foundation for Electoral Systems attempted to cut through the conceptual issues regarding defining electoral fraud, defining it as "deliberate wrong-doing by election officials or other electoral stakeholders, which distorts the individual or collective will of the voters" (Vickery and Shein 2012, page 9). Others have offered different definitions as to what constitutes electoral fraud, a conceptual problem that needs resolution in future research (Lehoucq 2003).

Furthermore, more theoretical development about when and where we might expect to see election manipulations attempted is necessary. Under what institutional, political, and strategic circumstances might fraud be attempted? How do political or electoral institutions shape the form that potential fraud might take? Are some legal procedures or institutions better, or worse, at preventing efforts are manipulation? How might demographic or cultural heterogeneities in a society mitigate or promote attempts at election fraud? Some scholars have already made important contributions to the development of theories of voter fraud. Magaloni (2010) shows that characteristics of the opposition, such as its capacity to mount a serious challenge of the election outcome, may affect the incumbent's incentives to engage in electoral fraud. Simpser and Donno (2012), in turn, show that election monitoring may have a negative impact on electoral integrity, by creating perverse incentives for incumbemts that motivate them to substitute traditional forms of electoral fraud by other types of manipulations of the electoral process. The continued development of theories will help applied researchers study both election integrity and electoral fraud.

Data availability and data quality are also issues for those who wish to study election integrity and fraud. Elections data can be notoriously difficult to collect, especially in the immediate aftermath of a disputed election. Even those who study these issues in the United States are often surprised to learn about the vast differences across the states in how much election return information is available to the public, and to see how variable in quality the 
available data can be (Alvarez, Ansolabehere and Stewart 2005). Election officials throughout the world should work to provide the type and quality of data necessary for the application of the forensics techniques that methodologists are developing and using; election integrity and democracy promotion organizations can assist in these efforts.

\section{References}

Alvarez, R. Michael, Stephen Ansolabehere, and Charles Stewart III. 2005. "Studying Elections: Data Quality and Pitfalls in Measuring the Effects of Voting Technologies." Policy Studies Journal, Volume 33, pages 15-24.

Alvarez, R. Michael, Thad E. Hall, and Susan D. Hyde. 2008. “Introduction: Studying Election Fraud.” In R. Michael Alvarez, Thad E. Hall, and Susan D. Hyde, editors, Election Fraud: Detecting and Deterring Electoral Manipulation, Washington, D.C.: The Brookings Institution Press, pages 1-17.

Alvarez, R. Michael and Jonathan N. Katz. 2008. "The Case of the 2002 General Election." In R. Michael Alvarez, Thad E. Hall, and Susan D. Hyde, editors, Election Fraud: Detecting and Deterring Electoral Manipulation, Washington, D.C.: The Brookings Institution Press, pages 149-61.

Collier, Paul and Pedro C. Vicente. 2012. "Violence, Bribery, and Fraud: The Political Economy of Elections in Sub-Saharan Africa." Public Choice, Volume 153, pages 117-47.

Eisenstadt, Todd A. 2007. "The Origins and Rationality of the 'Legal versus Legitimate' Dichotomy Invoked in Mexico's 2006 Post-Electoral Conflict.” PS: Political Science \& Politics, Volume 40, pages 39-43.

Frisina, Laurin, Michael C. Herron, James Honaker, and Jeffrey B. Lewis. 2008. "Ballot Formats, Touchscreens, and Undervotes: A Study of the 2006 Midterm Elections in Florida." Election Law Journal, Volume 7, Number 1, pages 25-47.

Hyde, Susan D. 2007. "The Observer Effect in International Politics: Evidence from a Natural Experiment." World Politics, Volume 60, pages 37-63.

Jefferson, David. 2007. "What Happened in Sarasota County?" The Bridge: Linking Engineering and Society, Volume 37, Number 2, Summer 2007, pages 17-23.

Lee, David S. 2008. "Randomized Experiments for Non-random Selection in U.S. House Elections," Journal of Econometrics, Volume 142, pages 675-97.

Lehoucq, Fabrice. 2003. "Electoral Fraud: Causes, Types and Consequences." Annual Review of Political Science, Volume 6, pages 233-56.

Levin, Ines, Gabe A. Cohn, Peter C. Ordeshook, and R. Michael Alvarez. 2009. "Detecting Voter Fraud in an Electronic Voting Context: An Analysis of the Unlimited Reelection Vote in Venezuela." Proceedings of the 2009 Electronic Voting Technology Workshop/Workshop on Trustworthy Elections (EVT/WOTE '09).

Magaloni, Beatriz. 2010. "The Game of Electoral Fraud and the Ousting of Authoritarian Rule." American Journal of Political Science, Volume 54, pages 751-65.

Mebane, Walter R., Jr. 2008. "Election Forensics: The Second-Digit Benfords Law Test and Recent American Presidential Elections." In R. Michael Alvarez, Thad E. Hall, and Susan D. Hyde, editors, Election Fraud: Detecting and Deterring Electoral Manipulation, Washington, D.C.: The Brookings Institution Press, pages 162-81.

Mebane, Walter R., Jr. 2010. “Fraud in the 2009 presidential election in Iran?” Chance, Volume 23, pages 6-15.

Myagkov, Mikhail, Peter C. Ordeshook, and Dimitri Shakin. 2009. The Forensics of Election Fraud: Russia and Ukraine. New York: Cambridge University Press.

Senyuva, Ozgehan. 2010. "Parliamentary elections in Moldova, April and July 2009.” Electoral Studies, Volume 29, pages 190-95. 
Simpser, Alberto and Daniela Donno. 2012. “Can International Election Monitoring Harm Governance?” Journal of Politics, Volume 74, pages 501-13.

Tucker, Joshua A. 2007. "Enough! Electoral Fraud, Collective Action Problems, and Post-Communist Colored Revolutions." Perspectives on Politics, Volume 5, pages 535-51.

Vickery, Chad and Erica Shein. 2012. "Assessing Electoral Fraud in New Democracies: Refining the Vocabulary." Washington, D.C., International Foundation for Electoral Systems.

Worden, Scott. 2010. "Afghanistan: An Election Gone Awry.” Journal of Democracy, Volume 21, pages 11-25.

About the Authors: Ines Levin is an Assistant Professor of Political Science at the University of Georgia. R. Michael Alvarez is a Professor of Political Science at Caltech, and is the co-director of the Caltech/MIT Voting Technology Project. 